\title{
Perceptual Justification: Factive Reasons and Fallible Virtues
}

\author{
Christoph Kelp and Harmen Ghijsen*
}

\begin{abstract}
Two different versions of epistemological disjunctivism have recently been upheld in the literature: a traditional, Justified True Belief Epistemological Disjunctivism (JTBED) and a Knowledge First Epistemological Disjunctivism (KFED). JTBED holds that factive reasons of the form " $S$ sees that $p$ " provide the rational support in virtue of which one has perceptual knowledge, while KFED holds that factive reasons of the form "S sees that $\mathrm{p}^{\prime \prime}$ just are ways of knowing that $\mathrm{p}$ which additionally provide justification for believing that $\mathrm{p}$. We argue that both accounts remain ultimately unsatisfactory. JTBED faces two formidable problems: first, it cannot account for animal knowledge, and, second, it does not offer a satisfactory account of how we access factive reasons. Although KFED can solve these two problems, it has some problems of its own. While intuitively knowledge is logically stronger than justified belief, on KFED it turns out to be weaker: knowledge does not entail justified belief, but justified belief does entail knowledge. Nevertheless, disjunctivists are right on at least a couple of points: we standardly justify our perceptual beliefs by appealing to factive reasons such as seeing that $\mathrm{p}$ and so factive reasons ought to play some role in our theory of justification. In addition, KFED's account of our access to factive reasons also is spot on. Rather than going disjunctivist, these insights can be suitably incorporated into a Knowledge First Virtue Epistemology (KFVE).
\end{abstract}

\footnotetext{
${ }^{*}$ Institute of Philosophy, KU Leuven, Kardinaal Mercierplein 2, BE-3000 Leuven, Email: christoph.kelp@hiw.kuleuven.be, harmen.ghijsen@hiw.kuleuven.be
} 


\section{Introduction}

Two different versions of epistemological disjunctivism have recently been upheld in the literature, both inspired by John McDowell's writings [e.g., 1982, 1994, 2008]. Duncan Pritchard [2012a] defends a version of epistemological disjunctivism according to which the fact that $S$ sees that $p$ provides the rational support in virtue of which $S$ knows that $p$. Pritchard can thus be taken to promote a version of a Justified True Belief (JTB) account of perceptual knowledge. In contrast, Alan Millar [2010] defends a Knowledge First (KF) version of epistemological disjunctivism, according to which seeing that $p$ is a way of knowing that $p$. While, in Millar's view, seeing that $p$ does not constitute the kind of rational support in virtue of which one knows that $p$, it does constitute a factive reason that serves to justify one's belief that $p$.

In this paper we argue that both versions of epistemological disjunctivism are ultimately unsuccessful. In $\S 1$, we discuss Pritchard's JTB version of the view (JTBED) and its purported motivations. In $\S 2$, we raise two problems for JTBED: first, it cannot account for animal knowledge, and, second, it does not offer a satisfactory account of how we can access factive reasons. In §3, we present Millar's knowledge first epistemological disjunctivism (KFED), and show that it can avoid these two problems. In $\S 4$ we argue that KFED has some problems of its own: while intuitively knowledge is logically stronger than justified belief, by Millar's lights, it turns out to be weaker: knowledge does not entail justified belief, but justified belief does entail knowledge. Finally, in $\S 5$, we argue that even though both versions of epistemological disjunctivism remain ultimately unsuccessful, disjunctivists have a number of important insights. We also show how these insights can be incorporated in a plausible account of how we can justify our perceptual beliefs.

\section{Pritchard's JTBED}

The core thesis of Pritchard's epistemological disjunctivism is as follows:

In paradigmatic cases of perceptual knowledge an agent, $S$, has perceptual knowledge that $\phi$ in virtue of being in possession of rational support, $R$, for her belief that $\phi$ which is both factive (i.e., $R$ 's obtaining entails $\phi$ ) and re- 
flectively accessible to $S$.

[Pritchard 2012a: 13]

According to Pritchard, an agent $S$ has paradigmatic ${ }^{1}$ perceptual knowledge in virtue of having a specific type of justification which ensures that the perceptual beliefs it supports are true. Perceptual knowledge is thus analysed as justified, true belief, although the type of justification is different from the type of justification that traditional JTB accounts have appealed to. Traditional accounts appealed to fallible reasons to provide the justification required for knowledge, reasons that are in principle compatible with the falsity of the belief in question - although knowledge of course requires that the belief in question is in fact true. In contrast, according to JTBED the relevant type of justification has to do with having reflectively accessible factive reasons, that is, reasons which entail that the beliefs they support are true.

The combination of factivity and accessibility is what makes JTBED counterintuitive. According to JTBED, a subject has reflective access to a factive reason in an epistemically good case, while it merely seems to the subject as if he had reflective access to such a reason in an introspectively indistinguishable epistemically bad case (e.g. in an hallucination). Pritchard goes to great lengths to argue that factivity and accessibility can be combined, but has surprisingly little to say about what exactly reflective accessibility amounts to other than that "the subject can come to know through reflection alone that she is in possession of this rational support" (ibid.). We will return to this point later on.

Let's get a little more concrete about the kind of reasons in play in perceptual knowledge. According to Pritchard:

The particular kind of rational support that the epistemological disjunctivist claims that our beliefs enjoy in paradigm cases of perceptual knowledge is that provided by seeing that the target proposition obtains. So when one has paradigmatic perceptual knowledge of a proposition, $p$, one's reflectively accessible rational support for believing that $p$ is that one sees that $p$. Seeing that $p$ is factive, however, in that if it is the case that one sees that $p$ then $p$

\footnotetext{
${ }^{1}$ In what follows, we will take Pritchard's restriction to paradigmatic cases of perceptual knowledge as read.
} 
must be true.

According to Pritchard, seeing that $p$ is, at least for the case of visual perception, what supports perceptual knowledge of $p$. For instance, when a subject $S$ is looking at a tree in epistemically favourable conditions such that there are no non-tree look-a-likes in the environment, $S$ 's perceptual faculties are working correctly, no deceivers are present, etc., then $S$ 's rational support for the belief that there is a tree is the fact that $S$ sees that there is a tree. This fact is reflectively accessible to $S$ and entails that there is a tree. In contrast, when a subject $S^{\prime}$ hallucinates a tree, then $S^{\prime}$ does not see that there is a tree, so the same kind of rational support is not present to be accessed by $S^{\prime}$. Of course, $S^{\prime}$ might think that he has the same kind of rational support while hallucinating a tree, but thinking that one has a certain reason comes apart from actually having this reason on the epistemological disjunctivist's picture.

What motivations are there to uphold such a view of perceptual knowledge? A first motivation is that it can easily accommodate our ordinary way of talking and thinking about perceptual knowledge. If someone challenges your claim to know that, e.g., your mutual friend is also at the party on the grounds that he usually does not go to parties, then you might well support your knowledge claim by saying that you know your friend is here because you see that he is standing over there. In this scenario, you justify your claim to know that your friend is at the party precisely by appealing to the factive reason that supported your knowledge in the first place. At least, that is a natural way to interpret what is going on in the imagined case. $^{2}$

A second motivation for JTBED, and, according to Pritchard, the most important one, is that it can capture key elements of both internalism and externalism in epistemology. It is for that reason that Pritchard portrays the view as being "the holy grail of epistemology" [2012a: 1]. Perceptual knowledge has to do with having reasons that are reflectively accessible, just as the internalist wants, but those reasons are also factive, thus securing the connection between epistemic support and truth that has been stressed by externalists. The first element allows for taking epistemic responsibility for one's beliefs,

\footnotetext{
${ }^{2}$ Note, however, that even Pritchard acknowledges that it might not be the only way [2012a: 17-8]. Note also that we offer an alternative in $§ 5$.
} 
while the second makes sure that one cannot be justified in a body of beliefs that still entirely falls short of the truth. ${ }^{3}$

If JTBED can indeed incorporate key internalist and externalist elements, then it would surely be a strong contender as a theory of perceptual knowledge. However, we think that Pritchard's epistemological disjunctivism encounters a number of serious problems. This will be the topic for our next section.

\section{Problems for JTBED}

\subsection{Animal knowledge}

One of Pritchard's core motivations for JTBED is that it reconciles internalism and externalism, by incorporating insights from both sides. In this way, JTBED is said to bring the holy grail of epistemology within reach. Unfortunately, on reflection, it is not clear that JTBED manages to accommodate all insights of internalists and externalists. In particular, we believe that JTBED struggles to accommodate a key externalist idea, to wit, that cognitively unsophisticated believers, like animals and small children, are capable of having knowledge, even when they are not cognitively sophisticated enough to be able to access to reasons for their beliefs. This problem of "hyperintellectualization" (Burge 2003: 503, see also Dretske e.g. 1981) is especially relevant to "accessibilist" accounts of perceptual knowledge on which one perceptually knows that $p$ only if one has a reflectively accessible reason for $p$ [e.g. Chisholm 1977, BonJour 1985,

\footnotetext{
${ }^{3}$ In addition, Pritchard provides a third motivation, to wit, that JTBED offers a particularly attractive solution to the problem of scepticism. This solution is neo-Moorean in that it grants that we can know that radical sceptical hypotheses are false. Pritchard takes JTBED's version of neo-Mooreanism to be preferable to externalist versions of the view because the latter "side-step" [Pritchard 2012a: 120] the problem, whereas the former can take it "head-on" [Pritchard 2012a: 134]. While we believe that a neo-Moorean approach to scepticism carries promise, we do not agree with Pritchard that JTBED-style neo-Mooreanism is preferable to its externalist competitors, for at least the following two reasons. First, it is not at all clear to us that this charge is legitimate to begin with. Second, we think that there is independent reason to think that externalism is preferable to JTBED, some of which we will develop in $\$ 2$ below. In fact, we believe the independent case for externalism to so strong as to render the charge of side-stepping the problem of scepticism small by comparison, even if it turned out to be legitimate. As a result, we are also inclined to favour an externalist version of neo-Mooreanism. That said, we will not take the time to argue this point in any detail here. Instead we will set aside the issue of scepticism and focus on the two other motivations for JTBED Pritchard offers.
} 
Steup 1999]. The externalist solution is to give an account of knowledge that does not require justification [e.g. Goldman 1967, Dretske 1981, Kornblith 2008], or to allow for at least a kind of justification which does not require any access to reasons [e.g. Goldman 1979, Lyons 2009, Kelp 2015a].

Since JTBED requires as an accessible reason for the perceptual belief that $p$ the fact that $S$ sees that $p$, it runs head-first into the hyper-intellectualization problem. What is required to access the factive reason that $S$ sees that $p$ is at the very least a belief on the part of the subject that he sees that $p$. Yet this is precisely what unsophisticated believers cannot achieve, and so, for these believers, the relevant factive reasons for perceptual knowledge and justification turn out not to be accessible. In consequence, unsophisticated believers are unable to have perceptual knowledge and justification, and so Pritchard cannot accommodate the externalist insight we started with.

It is not hard to see that Pritchard faces the hyper-intellectualisation worry because he embraces an accessibilist version of internalism. Given that this is so, one might think that the problem can be easily avoided. After all, there are other versions of internalism on the market. Most notably, there is mentalism according to which the justificatory status of one's beliefs supervenes on one's mental states [Feldman and Conee 2001]. Even unsophisticated agents can host a variety of mental states, including mental states of the kind that, according to mentalism, serve to provide justification for perceptual beliefs in adult human beings. As a result, it would seem that, unlike accessibilism, mentalism can steer clear of the hyperintellectualisation worry. So couldn't Pritchard avoid the problem by abandoning accessibilism in favour of a mentalist version of internalism?

JTBED is certainly compatible with mentalism. In fact, Pritchard himself considers this kind of view. The core idea here is that the relevant factive reasons are taken to be factive mental states in their own right. For instance, on this view, seeing that $p$ is a mental state in its own right. Moreover, it is quite plausible that a mentalist version of JTBED would solve the hyper-intellectualisation problem. After all, it is plausible that even unsophisticated agents can and often do see that $p$. If so, it is also plausible that they can have perceptual knowledge that $p$ in virtue of seeing that $p$.

As Pritchard himself realises, however, he is committed to a specif- 
ically accessibilist version of internalism [Pritchard 2012a: 41]. Why? Because of the way he motivates the internalist component of his view. Here is Pritchard:

[E]pistemic externalism entails that there is a significant degree of reflective opacity in the epistemic standing of our beliefs. This generates a fundamental difficulty for epistemic externalist positions, which is that it is hard on this view to capture any adequate notion of epistemic responsibility. For if the facts in virtue of which one's beliefs enjoy a good epistemic standing are not reflectively available to one, then in what sense is one even able to take epistemic responsibility for that epistemic standing?

[Pritchard 2012a: 2]

According to Pritchard, the reason why externalism fails is that it cannot offer an adequate account of epistemic responsibility. This, in turn, is because it would seem that no account of epistemic responsibility can be satisfactory unless it features an accessibility condition. It is not hard to see that if this argument works against externalism, it will be equally effective against mentalism. Or, to be more precise, it is equally effective against any version of mentalism that would solve the hyper-intellectualisation worry. After all, any such account will have to abandon the abovementioned accessibility requirement. As a result, while adopting mentalism in addition to accessibilism is an option for Pritchard, replacing the latter by the former isn't.

Here is another response to the hyper-intellectualisation worry one might give on behalf of Pritchard. Recall that Pritchard explicitly restricts his account of perceptual knowledge to paradigm cases of perceptual knowledge. If so, couldn't Pritchard simply deny that cases featuring unsophisticated agents are paradigm cases of perceptual knowledge? In that case, it is compatible with everything he says that unsophisticated agents can have perceptual knowledge after all.

This move simply won't do the trick here. To see this notice that Pritchard characterises paradigmatic perceptual knowledge as "perceptual knowledge which is gained in good+ cases" [Pritchard 2012a: 37]. A "good+ case" is defined as a case with the following five characteristics: (i) The agent's environment is epistemically hospitable and the relevant faculties producing the belief that $p$ are functioning properly (the case is "objectively epistemically good"). (ii) The agent has no defeaters for $p$ (the case is "subjectively epistemically good"). 
(iii) The agent has a veridical experience and a true belief that $p$. (iv) The agent sees that $p$. (v) The agent knows that $p$ [Pritchard 2012a: 29]. Now the problem for Pritchard is that cases in which unsophisticated agents acquire perceptual knowledge often exhibit all five characteristics. If so, by Pritchard's lights, these cases qualify as paradigm cases of perceptual knowledge. Since agents still don't satisfy the accessibility condition, the envisaged response on behalf of Pritchard remains unsuccessful. ${ }^{4}$

\subsection{An account of access}

Once one starts considering what it takes to access a factive reason, other problems show up for JTBED. Pritchard does not really explain what it means to have reflective access to a factive reason, other than that it "usually means that the subject can come to know through reflection alone that she is in possession of this rational support." [Pritchard 2012a: 13] But if reflective access is cashed out in terms of knowledge, then it seems reasonable to ask what the rational support of this knowledge in turn is. And now JTBED is either a) locked in a regress, each level requiring reflective access to, i.e. possible knowledge of, another reason, b) forced to acknowledge some kind of immediate ground for the knowledge that $S$ sees that $p$, or c) forced to reject any ground for this knowledge.

We take it that option (a) is simply not palatable (pace infinitists such as Klein e.g. 1998). Accepting option (b) is also problematic. For instance, suppose that one accepts option (b) and claims that experience provides the immediate ground for the knowledge that $S$ sees that $p$, in the sense that a subject having an experience that $p$ would

4 But couldn't Pritchard maintain that seeing that $p$ features an accessibility condition in the sense that one sees that $p$ only if one is in a position to know by reflection alone that one sees that $p$ ? If so, cases of perceptual knowledge by unsophisticated agents are not cases of seeing that $p$ and so do not qualify as paradigm cases of perceptual knowledge. Again this won't do. First, there is little hope that Pritchard's motivations for an accessibility condition on knowledge and justified belief will work for seeing that $p$ as well. Even if knowing and believing justifiably feature a responsibility condition and hence, according to Pritchard, an accessibility condition, there is little reason to think that seeing that $p$ also features a responsibility condition. As a result, there is no reason to think that seeing that $p$ will feature an accessibility condition. Second, as we have already indicated, it is independently plausible that unsophisticated agents may and often do see that $p$, e.g. when they acquire visual perceptual knowledge that $p$. In addition, then, there is positive reason to think that seeing that $p$ does not feature an accessibility condition. 
be immediately justified in believing that $S$ sees that $p$. We would then have a theory according to which experience that $p$ provides the rational support for the knowledge that $S$ sees that $p$, which in turn provides the rational support for $p$. Surely one should then cut out the middle man, and just go for the theory which claims that experience rationally supports the belief that $p$ directly. This strategy seems applicable for any ground JTBED could come up with: why not use that theory of immediate grounds directly for perceptual beliefs?

Option (c) suffers from the same problem. Suppose one claims that one knows that one sees that $p$ because of the reliability of the introspective mechanism that gives this belief as output. Then one could ask why the reliability of introspection is sufficient for knowledge of the fact that one sees that $p$, but the reliability of perception is not sufficient for knowledge of the fact that $p$. Again the problem is that for any proposal the question will arise why this could not be used directly to account for perceptual knowledge itself. ${ }^{5}$ JTBED thus seems hard pressed to provide an account of reflective access to factive reasons that does not make its own theory of perceptual justification superfluous.

\section{Millar's KFED}

We have seen that Pritchard's JTBED remains ultimately unsuccessful. In this section, we will turn to Millar's knowledge first version of epistemological disjunctivism (KFED). We will first outline the view and then argue that it can avoid the problems that Pritchard's JTBED encountered.

\subsection{Knowledge first}

The crucial difference between Millar's version of epistemological disjunctivism and that of Pritchard is that Millar takes knowledge to be the notion in terms of which justification should be explained. Millar thus follows Timothy Williamson [2000] in providing a knowledge first epistemology. One of the main reasons for taking this route is that it best reflects the way in which the concept of knowledge is applied in

\footnotetext{
${ }^{5}$ Note that once one does use proposal (b) or (c) to account for perceptual knowledge directly, the hyper-intellectualization problem will also be solved. This points to the fact that JTBED is not better off, and perhaps even worse off, than some of the more traditional internalist and externalist theories of justification.
} 
our everyday practices. We do not seem to apply the complex conditions that have been proposed in analyses of knowledge when we judge that $S$ knows $p$. What we do is different:

We happily count people as knowing that something is an $F$ when they see an $F$, and they may be presumed to have what it takes to tell of something they see that it is an $F$ from the way it looks. [...] The conceptual level at which we encounter the perceptual knowledge that we have, or that others have, is that of knowing that $p$ through seeing or otherwise perceiving that $p$, by means of an ability to tell that such a thing is so from the look or other appearance of what is perceived.

[Millar 2010: 133-4]

According to Millar, we should not try to give a reductive account of knowledge, but rather attempt to elucidate it by means of an investigation of the specific abilities exercises of which allow us to gain it, as it is precisely these abilities that we seem to latch on to when we ordinarily ascribe knowledge to someone.

In the case of perception, the relevant abilities are perceptual-recognitional abilities, which are ways of telling that things are so from their appearances, where appearances are just the way things look, sound, smell, etc. For subjects to have these abilities, it is important that the presented appearances are distinctive of the recognised objects in the sense that "[w]hen an appearance of something is distinctive of Fs, not easily could something have this appearance and not be an $F^{\prime \prime}$ [Millar 2010: 125]. Perceptual-recognitional abilities are thus environment-dependent. This accords with the intuition that Barney cannot know that there is a barn in front of him when he is looking at one of the few real barns in fake barn county. In such a scenario, there are too many fake look-a-likes around that make the appearance of the real barn no longer distinctive of a real barn. Millar even goes as far as to claim that Barney, when in fake barn county, does not just fail to exercise the requisite perceptual-recognitional ability, but even lacks this ability altogether [Millar 2010: 126].

In contrast, a subject fails to exercise a perceptual-recognitional ability that he does possess in the situation where the environment is in fact favourable, but the subject nevertheless does not recognise something for what it is. This might happen when a subject is careless in his judgement, or is just unlucky enough to encounter the only fake look-a-like in the entire environment. In any case, the important 
point is that, as Millar construes it, the notion of exercise of an ability is a success notion [Millar 2010: 125]: one cannot exercise an ability to $\phi$ unless one $\phi$ s. Applied to the case of perceptual-recognitional abilities this means that one cannot exercise a perceptual-recognitional ability without knowing that such-and-so is the case.

Another crucial point for Millar is that the distinctive appearances that are required for having a perceptual-recognitional ability do not serve as evidence on the basis of which one concludes that something is an $F$. Millar provides three convincing reasons for this claim [Millar 2010: 121-22]. First, thinking of experiences as evidence gets the phenomenology of perceptual recognition wrong: we are not aware of basing our judgement that, say, Bill is here on the appearance that Bill presents. Second, people are often able to recognise persons or things without being able to articulate on the basis of which features precisely they recognised them. The case that springs to mind is that of the chicken-sexers who are able to recognise the sex of a chick even though they do not know how they do it and sometimes even have false beliefs about how they do it (they believe that they do it by sight, but they actually do it by smell). ${ }^{6}$ Of course one might hold that this just shows that chicken-sexers do not know the sex of a chick, but then the same will appear to be true for many other instances of perceptual recognition. Third, thinking of appearances as evidence for recognitional judgements actually gets the order of understanding the wrong way. Creatures capable of perceptual knowledge need not be capable of thinking in terms of appearances, nor does it seem likely that we first think in terms of appearances and then go on to think in terms of things belonging to a certain kind.

\subsection{Perceptual justification}

It should be clear that Millar thinks that perceptual knowledge is not to be reduced to beliefs that are justified on the basis of some kind of evidence. But this raises a question as to what makes his view epistemological disjunctivist. Consider again what Pritchard takes to be the main thesis of epistemological disjunctivism:

In paradigmatic cases of perceptual knowledge an agent, $S$, has perceptual knowledge that $\phi$ in virtue of being in

\footnotetext{
${ }^{6}$ Note that it does not appear all too important whether this example is actual. Even if this description is not accurate of chicken-sexers, relevantly similar examples do seem possible [cf. Pritchard 2006: 61].
} 
possession of rational support, $R$, for her belief that $\phi$ which is both factive (i.e., $R^{\prime}$ s obtaining entails $\phi$ ) and reflectively accessible to $S$.

[Pritchard 2012a: 13]

Since Millar does not agree with Pritchard that an agent has perceptual knowledge in virtue of being in possession of factive rational support, Millar's theory would not count as epistemological disjunctivist according to this definition. But Millar does agree that an agent often has factive, reflectively accessible rational support in paradigmatic cases of perceptual knowledge:

[E]pisodes in which I come to know that an animal I am looking at is a zebra are, barring rare, dire confusion, or rare and bizarre deception, episodes in which the fact that I see that the animal is a zebra is available to me as a reason to believe that it is a zebra and to continue to believe that it was thereafter. The intimate connection between perceptual knowledge and justified belief is accommodated by acknowledging that the fact that I see that the animal is a zebra can constitute a reason I have to take it to be one. But instead of explaining the knowledge as, so to speak, built up from justified belief, we treat the knowledge as what enables one to be justified in believing.

[Millar 2010: 139]

On Millar's account, justification has to do with being in possession of clinching reasons for belief, i.e. reasons that settle it that the belief is true. Possession of such reasons in turn implies that a subject "[stands] in some relation to a (distinct) consideration in view of which [the subject] is justified" [Millar 2010: 112]. Thus, even though Millar does not think that knowledge must be built up from evidentially supported beliefs, he does take justification to consist in having accessible, clinching reasons for belief. In paradigmatic cases of visual perceptual knowledge, these reasons are constituted by the fact that $S$ sees that $p$, and this is what makes his view a version of epistemological disjunctivism. Subjects in epistemically good cases have access to factive reasons that are not available to subjects in epistemically bad cases, even though the cases might be introspectively indistinguishable.

Millar even goes further than Pritchard in explaining how subjects in good cases can access factive reasons. Subjects are able to know 
that they see that $p$ by exercising a higher-order recognitional ability [Millar 2010: 181-2]. These higher-order recognitional abilities differ from perceptual-recognitional abilities in that they do not latch on to the appearances of objects. After all, no object has a look that is distinctive for being seen by me. In this case it rather is my having a certain experience that is distinctive of an object's being seen by me [Millar 2011: 339-40]. But in other respects higher-order recognitional abilities perfectly parallel first-order recognitional abilities.

\subsection{Solving the problems of JTBED}

Millar's KFED has some clear advantages over Pritchard's JTBED. First of all, KFED does not face the problem of hyper-intellectualization with regard to perceptual knowledge. Animals and small children can also exercise perceptual-recognitional abilities in part because this does not involve basing on beliefs on reflective accessible reasons. This means that it is possible for cognitively unsophisticated believers to see that, and thereby know that, such-and-such is the case.

Second, KFED provides a clear account of access that is not available to JTBED. According to KFED, access to factive reasons is provided by higher-order recognitional abilities: one (usually) knows that one sees that $p$ because one recognises that one sees that $p$. Accessing a factive reason thus comes down to knowing that the reason obtains in a way that parallels the way in which we are able to have perceptual knowledge.

\section{Problems for KFED}

Despite the good result with regard to JTBED's problems, KFED has problems of its own. More specifically, Millar's account has the bizarre consequence that justified belief turns out to be logically stronger than knowledge, while intuitively it is logically weaker. That is to say, on Millar's account, knowledge does not entail justified belief, while justified belief does entail knowledge, while intuitively it is the other way around: knowledge entails justified belief but justified belief does not entail knowledge. In what follows, we will argue for both parts of this untoward consequence of Millar's account. 


\subsection{Knowledge does not entail justified belief}

To see why, according to Millar, knowledge does not entail justified belief, just consider cognitively unsophisticated believers again. Although KFED can accommodate the possibility of animal knowledge, it cannot accommodate what one might call 'animal justification' for visual perceptual beliefs. Such justification requires that a subject be able to access the fact that he sees that $p$, which requires a higherorder recognitional ability. Now, even though unsophisticated believers might have perceptual-recognitional abilities, it's implausible that they also have higher-order recognitional abilities. This means that KFED does succumb to the hyper-intellectualization objection with regard to the justification of unsophisticated believers. Unsophisticated believers are never justified in their beliefs that $p$, even if they do know that $p$.

A similar scenario of knowledge without justification should also be possible for adult human subjects. Given that there are two distinct recognitional abilities at play in providing respectively knowledge and justification, it should be possible that the lower-order perceptual-recognitional ability is successfully exercised while the higher-order recognitional ability is not. The chicken-sexer case might be used as an instance of this possibility. Although the chickensexer knows, e.g., that the chick is female because of his perceptualrecognitional ability, he is not in a position to access the relevant factive reason for his belief, thanks to his false beliefs about how he knows. KFED would have the consequence that the chicken-sexer in this scenario knows that the chick is female even though he does not justifiably believe that the chick is female. And this certainly appears to be an odd result.

\subsection{Justified belief entails knowledge}

Let's turn to the second untoward consequence of Millar's account, viz. that justified belief entails knowledge. The reason Millar is committed to this is that, according to him, possession of the kinds of factive reasons required for justified perceptual belief is sufficient for knowing. For instance, in the case of the visual perceptual belief that $p$, justification requires that one see that $p$. At the same time, seeing that $p$ is said to be a way of knowing that $p$. In consequence, one will satisfy Millar's conditions for justified belief that $p$ here only if one knows that $p$. Justified perceptual beliefs that fall short of knowledge turn out to be impossible. 
To see why this is implausible, consider the case of Barney one more time. Recall that Barney is looking at one of the few real barns in fake barn county and acquires a true visual perceptual belief that he is looking at a barn. Intuitively, it is highly plausible that Barney's belief, whilst falling short of knowledge, is both justified and true. As we have already seen, Millar has no problems with accounting for the intuition that Barney doesn't know that the structure he is looking at is a barn. If Barney doesn't know that he is facing a barn, however, then, according to Millar, he also does not see that he is facing a barn. But if he doesn't see that he is facing a barn he does not have the kind of factive reason that is required for his corresponding visual perceptual belief to be justified. ${ }^{7}$

It will not come as a surprise that Millar is well aware of this problem. He ventures to address it in the following passage:

[T]he notion of justified belief that figures in traditional analysis and in descriptions of Gettier cases is [...] very weak. It has everything to do with a kind of reasonableness that renders one blameless in thinking that something is so, but little to do with the kind of well-groundedness that settles that something is so and on that account entitles one to take it to be so.

[Millar 2010: 102]

Millar's idea is to distinguish between two varieties of justified belief, a strong and a weak one. The strong variety is captured by his account of justification. In contrast, the weak variety is unpacked in terms of blamelessness. For a belief to possess justification of the weak sort is for it to enjoy "a kind of reasonableness that renders one blameless in thinking that something is so" (ibid.). Crucially, Millar acknowledges that agents in Gettier cases do not possess the strong variety of justification. In order to address the intuition that the beliefs of agents in Gettier cases are justified Millar goes on to claim that their beliefs are justified in the weak sense: they are reasonable

\footnotetext{
${ }^{7}$ Note that this problem can in principle be avoided by rejecting that seeing that $p$ is a way of knowing that $p$. At the same time, it is hard to deny that seeing that $p$ is at least factive. In consequence, even if one rejects that seeing is a way of knowing, it still follows from Millar's account that justified perceptual belief is factive, which is almost equally bad and leaves Millar open to the new evil demon problem [Lehrer 1983, Cohen 1984] and counterexamples involving the unlucky counterparts of gettiered agents (who end up with intuitively justified but false beliefs).
} 
in a way that renders the agents blameless. ${ }^{8}$

Unfortunately, there is reason to believe that Millar's explanation is ultimately unsatisfactory. To bring this out consider the case of Ben who belongs to an isolated and benighted community the members of which share a common belief that thunderstorms indicate that their twenty-eared deity is about to scratch its largest left ear. Just now Ben is witnessing a thunderstorm and comes to believe that the deity is about to scratch an ear. Given the common belief of Ben's community concerning the link between thunderstorms and ear-scratchings, the belief Ben acquires in this case is reasonable in a way that renders him blameless in believing as he does. As a result, Ben's belief does enjoy the weak variety of justification that Millar countenances and uses to explain the intuition of justification in the above cases. To see the problem for Millar, notice that there is an epistemically important difference between Ben on the one hand and Barney on the other. Where Ben's belief does not have any connection to truth whatsoever, Barney acquires his beliefs in a way that usually leads to true beliefs. To make the point less externalist, although Ben may have done nothing epistemically wrong in coming to believe as he does, Barney appears to have done something epistemically right in coming to believe as he did. By explaining the intuitions of justification in the problem cases in terms of blamelessness, KFED is bound to collapse an epistemically important distinction between Ben on the one hand and Barney on the other. ${ }^{9}$

\section{Discursive Justification}

We have argued that both versions of epistemological disjunctivism are ultimately unsuccessful. JTBED encounters the problem of animal knowledge and the problem of providing a satisfactory account of reflective accessibility. On the other hand, KFED has the untoward

\footnotetext{
${ }^{8}$ Notice also that the same line will serve to account for the intuition in cases of justified false beliefs.

9 See [Gettier 1963, Shope 1983, Lycan 2006] for more on Gettier cases. The case of Ben is a variation of a case by Goldman [1988]. See [Kelp 2011a] and [Bird 2007] for similar arguments that blamelessness and justification come apart. It is worth noting that, while Pritchard does not explicitly address the question whether agents like Barney can have justified beliefs, his treatment of the new evil demon problem suggests that he would favour an account of the intuition of justification in terms of blamelessness as well [Pritchard 2012a: 42-4]. If so, Pritchard is of course bound to run into exactly the same problem as Millar does.
} 
consequence that justified belief is logically stronger (rather than logically weaker) than knowledge.

But perhaps we haven't been as charitable in our treatment of epistemological disjunctivism as we could have been. Recall that part of the motivation for disjunctivism was that it is common practice to justify beliefs by appealing to factive reasons. Relatedly, at some point Millar notes that "justified belief involves being in a position to justify one's belief" [2010: 113, n.15]. It is not hard to see that some of the arguments in the previous sections can be taken to put pressure on this claim as well. For instance, if we want to allow that cognitively unsophisticated agents can have perceptually justified beliefs, then Millar's claim is bound to turn out false as well. After all, such agents will not be in a position to justify their beliefs.

Crucially, however, instead of taking this point to further confirm the case against epistemological disjunctivism, we might also take it as an indication that its champions have been after a different kind of justification. More specifically, let's distinguish between epistemic (or e-) justification and discursive (or d-) justification, where e-justification is the kind necessary for knowledge and d-justification the kind required to be in a position to properly justify one's belief. What we have argued thus far is that disjunctivism does not work as an account of e-justification. However, perhaps a more charitable way of reading disjunctivism is as an account of d-justification.

Let's briefly recapitulate what epistemological disjunctivism, interpreted now as an account of d-justification, would look like. We will here focus on Millar's version. Suppose I see that $p$ and consequently perceptually know that $p$. In order to have d-justification for $p$, I must be in a position to justify my belief that $p$ and that, in turn, requires me to possess and be able to access a reason for $p$. The reason is of course the factive reason of seeing that $p$ and access is analysed in terms of the exercise of an ability to know. More specifically, when called upon to justify my perceptual belief that $p, \mathrm{I}$ exercise my higher-order recognitional ability and thus access a reason for believing that $p$, to wit, that I see that $p$. I am then free to justify my belief that $p$ by appealing to my reason for $p$, viz. that I see that $p$.

We agree with Millar that this works perfectly fine for the good case, i.e. the case in which my perceptual belief that $p$ qualifies as knowledge. Unfortunately, there are once again problems on the horizon. To see this, notice that it is highly plausible that it is pos- 
sible to have d-justification in Gettier cases involving perceptual beliefs. For instance, Barney very plausibly not only has e-justification, but also d-justification. However, if d-justification is analysed along the lines suggested on behalf of Millar, we will be hard pressed to accommodate this datum. Here is why. To begin with, (i) seeing is a way of knowing and so one sees that $p$ only if one knows that $p$. Moreover, (ii) access to reasons is unpacked in terms of recognitional abilities, that is, in terms of abilities to know. Finally, (iii) exercise of ability is taken to be a success notion: one cannot exercise an ability to $\phi$ unless one $\phi$ s. From (ii) and (iii) it follows that if one does access the proposition that one sees that $p$, then one knows that one sees that $p$. Given the factivity of knowledge and (i), it follows that one accesses the proposition that one sees that $p$ only if one knows that $p$. On Millar's account, then, one can have d-justification for the belief that $p$ only if one knows that $p$.

The question we'd like to address is whether Millar's account can be tweaked in order to accommodate d-justification in the cases of belief that falls short of knowledge. We think the answer is 'yes'. Of course, in order to achieve this, we need to reject at least one out of (i), (ii) and (iii). In this paper, we'd like to explore the prospects for an account of d-justification that rejects (iii). ${ }^{10}$

One immediate difficulty for this approach is that we are now in need of an alternative account of the notion of exercise of ability. Moreover, given that the output of an exercise of ability is not, or at least not always, knowledge, we are facing another difficulty. After all, if I know for instance, that I see that $p$, it seems that I can indeed properly justify $p$ by appealing to my seeing that $p$. If the output is not knowledge this is no longer clear. Suppose I have come to believe

\footnotetext{
${ }^{10}$ There is some reason to think that this option is the only adequate one. To see this, notice first that it is very plausibly possible to have d-justification for false beliefs. Even if we rejected (i), it remains very plausible that seeing that $p$ is factive. Given that we hold on to (ii) and (iii), it still follows that one can access the proposition that one sees that $p$, only if $p$ is true. We would still be unable to accommodate the possibility of $\mathrm{d}$-justified but false beliefs. Moreover, notice that the standard way of analysing the notion of a recognitional ability, if not as an ability to know, is as an ability to form true beliefs [e.g. Greco 2010, Sosa 2007]. Thus, even if, in addition, we abandon (ii) and unpack the notion of a recognitional ability as an ability to form true beliefs, so long as we hold on to (iii), one exercises the higher-order recognitional ability only if one truly believes that one sees that $p$. Given the factivity of seeing, again one accesses the proposition that one sees that $p$ only if $p$. In that case, again, it turns out to be impossible to have d-justification for a false belief.
} 
that I see that $p$ based on a toin-coss. In that case, even though I might go on to appeal to my seeing that $p$ in order to justify my belief that $p$, it now seems that my doing so will not allow me to mount a proper justification of $p$. So, we need to specify what the output of an unsuccessful exercise of a recognitional ability is and we need to show that, whatever it turns out to be, it can provide an adequate basis for a proper justification of the target proposition.

Fortunately, all of these difficulties can be overcome. In fact, one of us has elsewhere [Kelp 2015a,b] defended a view called "knowledge first virtue epistemology" (KFVE) that will give us exactly what we need here. In what follows we provide a brief sketch of the relevant aspects ${ }^{11}$ of this view. ${ }^{12}$

KFVE combines a knowledge first with a virtue theoretic approach to epistemology. In order to get a clearer view of what this account amounts to, we'd first like to say a few more things about virtue epistemology. Virtue epistemology ventures to analyse knowledge and justified belief in terms of abilities. Roughly, abilities are construed as dispositions to perform well, i.e. to produce successful performances. For instance, to have the ability to hit the target in target archery is to have a disposition to produce shots that hit the target.

The rough account of abilities needs to be finessed. To see this, let's return to the archery example. Notice that an agent may have the ability to hit the target of target archery even though he is not disposed to produce shots that hit the target whilst asleep, drunk, distracted, etc. or when shooting in strong winds, at sabotaged targets, etc. This motivates a relativisation of abilities to conditions concerning the shape of the agent (SH) and situational conditions (SI). In case of archery ability, the ability to hit the target is relative to the agent's being awake, sober, sufficiently concentrated, etc. $(=\mathrm{SH})$ and to there being normal winds, no sabotaged targets, etc. (= SI).

\footnotetext{
${ }^{11}$ Note that our presentation of KFVE leaves out some details of the view. For a full development of KFVE see [Kelp 2015a].

${ }^{12}$ It is not hard to see that our account of d-justification is also available to process reliabilists [e.g Goldman 1979, Lyons 2009] and traditional virtue epistemologists [e.g. Sosa 2007, Greco 2010] (at least given the account of abilities sketched below). In fact, one of us briefly outlines the contours of a process reliabilist account higher-order beliefs briefly in [Ghijsen 2014]. The main reason we are opting for a KFVE implementation of the account here is that it allows us to stay as close as possible to Millar's own account, which also falls within the knowledge first paradigm. For arguments that virtue epistemology is preferable to process reliabilism see [e.g. Greco 2000, 2010]. See [Kelp 2015a] for reasons to favour KFVE over traditional virtue epistemology.
} 
Notice, furthermore, that an agent may have more than one way of producing performances. For instance, an archer may have more than one way of producing shots. To keep things simple, let's suppose he has two ways: he can shoot with his right hand or with his left. Suppose he is disposed to perform well when producing shots in one way (with his right, say) but not the other (with his left, say). Suppose, finally, that our archer is disposed to produce shots with his left hand. His dominant way of shooting is with his left. In that case, there is a clear sense in which our archer is not disposed to hit the target. Even so, our archer possesses an ability to hit the target, viz. when shooting with his right. It's just that he is disposed not to exercise this ability. These considerations suggest that abilities are relative not only to $\mathrm{SH}$ and SI, but also to ways of producing performances. Abilities are dispositions to perform well in suitable $\mathrm{SH}$ and SI via certain ways of performance production.

This account of abilities is combined with the following account of the exercise of ability: to exercise a certain ability is to produce a performance via the way of performance production underlying it. For instance, for our archer to exercise his ability to hit the target is for him to produce a shot via the way of shot production underlying his ability. Crucially, the idea here is that unsuitable SH prevent the agent from using his way of performance production and hence from exercising his ability. For instance, when our archer is asleep, drunk, distracted, etc., he is not in a position to use the way of shooting that underlies his ability to hit the target in more favourable $\mathrm{SH}$. As a result, in those $\mathrm{SH}$ he is not in a position to exercise this ability. In contrast, unsuitable SI do not prevent the agent from exercising his ability. This happens when our agent takes a shot that would have hit the target had it not been blown off its trajectory by a gust of wind or had the target not been protected by a forcefield. In these cases our agent produces his shot in the same way that constitutes an ability to hit the target in more favourable SI. So, here he does exercise his ability.

It is now easy to see that the present account differs from Millar's in that the notion of exercise of ability is not a success notion. That is to say, it is possible to exercise an ability and produce an unsuccessful performance. In fact, this is exactly what happens in the above cases in which our archer's shot is blown off target or the target he shoots at is protected by a forcefield.

Virtue epistemology uses an account of abilities and their exer- 
cise, like the one just sketched, to offer accounts of knowledge and e-justified belief. Standard virtue epistemology identifies a (perhaps the) fundamental kind of epistemic success with true belief. Accordingly, one important class of epistemic abilities are abilities to form true beliefs. E-justified belief is then identified with belief that is produced by the exercise of such an epistemic ability. Knowledge is belief that is successful because of the exercise of such an epistemic ability. ${ }^{13}$

In contrast, KFVE countenances knowledge as a (perhaps the) fundamental kind of epistemic success. Accordingly, one important class of epistemic abilities are abilities to know. While it is not hard to see that KFVE cannot hope to offer a reductive analysis of knowledge in terms of such epistemic abilities, [Kelp 2015a] argues that the following ability condition knowledge holds (and does so non-trivially): one knows that $p$ only if one believes $p$ via the exercise of an ability to know in favourable SI. Most importantly for present purposes, however, the following reductive analysis of e-justified belief is proposed: one e-justifiably believes that $p$ if and only if one believes that $p$ via the exercise of an ability to know. In other words, the idea is that knowledge requires belief from ability to know in favourable situational conditions and e-justified belief is belief from ability to know, no matter whether situational conditions are favourable or not.

It may be worth noting that KFVE avoids the problems outlined for Pritchard and Millar in $\S 2$ and $\S 4$ above, where these are understood as accounts of e-justification.

First, it is easy to see that KFVE allows for perceptual knowledge (and e-justified belief) in unsophisticated agents. After all, what matters to perceptual knowledge and e-justified belief is acquiring beliefs via the right kinds of ability rather than accessible reasons. Since it is uncontroversial that animals and small children have these abilities and frequently acquire beliefs via their exercise, they can have perceptual knowledge and e-justified belief.

Second, on the present accounts of knowledge and e-justified belief, knowledge entails e-justified belief. After all, by the condition on knowledge, knowledge requires belief produced via an exercise of ability to know in suitable SI, which in turns requires belief produced via an ability to know. By the account of e-justified belief, this

${ }^{13}$ For more on standard virtue epistemology see e.g. [Greco 2010, 2012, Sosa 2007, 2011, Pritchard 2010, 2012b]. One of us has also explored the prospects of versions of this view in [Kelp 2011b, 2013, 2014a,b]. 
is sufficient for e-justified belief.

Third, e-justified belief does not entail knowledge. To see this, notice that agents in Gettier cases such as Barney turn out to have e-justified beliefs. Barney acquires his beliefs that he is facing a barn in a way that constitutes an ability to know in more favourable SI. On the above account of the exercise of ability, he acquires his beliefs via an ability to know (albeit in unsuitable SI). Given KFVE's account of e-justified belief, this means that his belief is e-justified. ${ }^{14}$

With KFVE in play, we can now see how we can make sense of djustification of perceptual belief via factive reasons in the problematic bad cases.

In essence, the story parallels Millar's fairly closely. Suppose I have an e-justified perceptual belief that $p$. To move straight to the problem cases, suppose my belief falls short of knowledge that $p$ (because I am gettiered or else my belief is false). Suppose I am called upon to justify my belief. Just as in the good case, I exercise a higher-order recognitional ability, which outputs a belief that I see that $p$. Of course, since I do not know that $p$, my belief that I see that $p$ is false and hence does not qualify as knowledge. Even so, I acquire it in exactly the same way in which, in more favourable SI, I come to know that I see that $p$. By the above account of exercises of abilities, I acquire my belief via the exercise of an ability to know. Moreover, since my belief that I see that $p$ is produced via the exercise of an ability to know, by the above account of e-justified belief, my belief that I see that $p$ is e-justified. Again, I am free to justify my belief that $p$ by appealing to my reason for $p$, viz. that I see that $p$.

It is easy to see how the account addresses the difficulties that arose by allowing for unsuccessful exercises of abilities mentioned above. First, we have offered an alternative account of exercises of abilities in terms of uses of ways of performing on which unsuccessful exercises of abilities are possible. Second, given KFVE, in case of abilities to know, the outputs of exercises of these abilities are ejustified beliefs. While a completely unjustified belief that I see that $p$ (e.g. one that is based on a coin-toss) does not serve to provide an adequate basis for a proper justification of $p$, an e-justified belief that I

${ }^{14}$ Note also that KFVE can avoid the new evil demon problem [Kelp 2015b]. Agents in radical sceptical scenarios also form their perceptual beliefs in the same ways as they would have had they not been in a sceptical scenario, i.e. via exercise of abilities to know. Moreover, the same goes for unlucky counterparts of agents in Gettier cases. In consequence, in both types of case KFVE predicts that the agents' beliefs are e-justified. 
see that $p$ very plausibly does. In this way, we now have an account of d-justification for perceptual belief in which factive reasons-notably seeing that $p$-play a central part and which allows for $\mathrm{d}$-justification even in cases of belief that falls short of knowledge.

\section{Conclusion}

It comes to light that epistemological disjunctivism remains unsatisfactory both in its traditional (JTB) and its knowledge first incarnation. More specifically, epistemological disjunctivism fails not only as an account of e-justification but also if it is interpreted, perhaps more charitably, as an account of d-justification. That said, we believe that disjunctivists were right on at least a couple of points: we standardly justify our perceptual beliefs by appealing to factive reasons such as seeing that $p$ and so factive reasons ought to play some role in our theory of justification. In addition, we think Millar's claim that access of factive reasons proceeds via the exercise of higher-order recognitional abilities is spot on. We have argued that in conjunction with KFVE, these insights can be used to offer an account of d-justification of perceptual beliefs in which perceptual beliefs are d-justified by factive reasons of the form $I$ see that $p$.

\section{References}

Bird, A. (2007). Justified judging. Philosophy and Phenomenological Research, 74(1):81-110.

BonJour, L.. (1985). The Structure of Empirical Justification. Cambridge, MA: Harvard University Press.

Burge, T. (2003). Perceptual entitlement. Philosophy and Phenomenological Research, 67(3):503-548.

Chisholm, R. (1977). Theory of Knowledge, $2^{\text {nd }}$ Edition. Englewood Cliffs: Prentice Hall.

Cohen, S. (1984). Justification and truth. Philosophical Studies, 46(3):279-295.

Dretske, F. (1981). Knowledge and the Flow of Information. Cambridge, MA: MIT Press. 
Feldman, R. and Conee, E. (2001). Internalism defended. American Philosophical Quarterly, 38(1):1-18.

Gettier, E. (1963). Is justified true belief knowledge? Analysis, 23(6):121-123.

Ghijsen, H. (2014). Phenomenalist dogmatist experientialism and the distinctiveness problem. Synthese, 191(7):1549-1566.

Goldman, A. (1967). A causal theory of knowing. The Journal of Philosophy, 64(12): 357-372.

Goldman, A. (1976). Discrimination and perceptual knowledge. The Journal of Philosophy, 73(20): 771-791.

Goldman, A. (1979). What is justified belief? In Pappas, G., editor, Knowledge and Justification. Dordrecht: Springer.

Goldman, A. (1988). Strong and weak justification. Philosophical Perspectives, 2:51-69.

Greco, J. (2000). Agent reliabilism. Philosophical Perspectives, 13:273296.

Greco, J. (2010). Achieving Knowledge. Cambridge: Cambridge University Press.

Greco, J. (2012). A (different) virtue epistemology. Philosophy and Phenomenological Research, 85(1):1-26.

Kelp, C. (2011a). Not without justification. Dialectica, 65 (4):581-95.

Kelp, C. (2011b). In defence of virtue epistemology. Synthese, 179(3):409-33.

Kelp, C. (2013). Knowledge: the safe-apt view. Australasian Journal of Philosophy, 91(2):265-78.

Kelp, C. (2014a). Epistemology extended. Philosophical Issues, 24(1):230-252.

Kelp, C. (2014b). Knowledge, understanding, and virtue. In Fairweather, A., editor, Virtue Epistemology Naturalized: Bridges between Virtue Epistemology and Philosophy of Science. Dordrecht: Springer. 
Kelp, C. (2015a). Knowledge first virtue epistemology (forthcoming). In Carter, A., Gordon, E. and Jarvis, B., editors, Knowledge First: Approaches in Epistemology and Mind. Oxford: Oxford University Press.

Kelp, C. (2015b). Justified belief: knowledge-first style. Manuscript.

Klein, P. (1998). Foundationalism and the infinite regress of reasons. Philosophy and Phenomenological Research, 58(4):919-925.

Kornblith, H. (2008). Knowledge needs no justification. In Smith, Q., editor, Epistemology: New Essays. Oxford: Oxford University Press.

Lehrer, K. and Cohen, S. (1983). Justification, truth, and coherence. Synthese, 55(2):191-207.

Lycan, W. (2006). On the Gettier Problem problem. In Hetherington, S., editor, Epistemology Futures. Oxford: Oxford University Press.

Lyons, J. (2009). Perception and Basic Beliefs. Zombies, Modules, and the Problem of the External World. New York: Oxford University Press.

McDowell, J. (1982). Criteria, defeasibility, and knowledge. Proceedings of the British Academy 68:455-479.

McDowell, J. (1994). Mind and world: With a new introduction. Cambridge, MA: Harvard University Press, 1996 edition.

McDowell, J. (2008). The disjunctive conception of experience as material for a transcendental argument. In Haddock, A. and Macpherson, F., editors, Disjunctivism: Perception, Action, Knowledge. Oxford: Oxford University Press.

Millar, A. (2010). Knowledge and recognition. In Pritchard, D., Millar, A., and Haddock, A., editors, The Nature and Value of Knowledge: Three Investigations. Oxford: Oxford University Press.

Millar, A. (2011). How visual perception yields reasons for belief. Philosophical issues, 21(1):332-351.

Pritchard, D. (2006). What is this Thing called Knowledge? New York: Routledge, 2010 edition.

Pritchard, D., Millar, A. and Haddock, A. (2010). The Nature and Value of Knowledge. Oxford: Oxford University Press. 
Pritchard, D. (2012a). Epistemological Disjunctivism. Oxford: Oxford University Press.

Pritchard, D. (2012b). Anti-luck virtue epistemology. The Journal of Philosophy 109(3):247-279.

Shope, R. (1983). The Analysis of Knowledge: A Decade of Research. Princeton, NJ: Princeton University Press.

Sosa, E. (2007). A Virtue Epistemology. Apt Belief and Reflective Knowledge. Vol. 1. Oxford: Oxford University Press.

Sosa, E. (2011). Knowing Full-Well. Princeton, NJ: Princeton University Press.

Steup, M. (1999). A defence of internalism. In Pojman L., editor, The Theory of Knowledge: Classical and Contemporary Readings, $2^{\text {nd }}$ edition, Belmont: Wadsworth Publishing.

Williamson, T. (2000). Knowledge and Its Limits. Oxford: Oxford University Press. 